\title{
Real-Time Monitoring of Laser Surface Hardening of Ferrous Alloys
}

Zhiyue Xul, Keng H. Leong2 and Claude B. Reed 1

1Technology Development Division, Argonne National Laboratory, 9700 S. Cass Avenue, Building 360, Argonne, II 60439

2Applied Research Laboratory, The Pennsylvania State University State College, PA 16804

Submitted for publication in the

RECEIVED

JAN 182000

OSTI

Proceedings of the International Conference on

Applications of Lasers and Electro-Optics (ICALEO'99)

San Diego, California

November 15-18, 1999

The submitted manuscript has been authored by

a contractor of U.S. Govemment under contract

No. $W-31$ - 109-ENG-38. Accordingly, the

U.S. Government retains for nonexclusive,

royalty-free license to publish or reproduce the

published form of this contribution, or allow

others to do so, for U.S. Government purposes. 


\section{DISCLAIMER}

This report was prepared as an account of work sponsored by an agency of the United States Government. Neither the United States Government nor any agency thereof, nor any of their employees, make any warranty, express or implied, or assumes any legal liability or responsibility for the accuracy, completeness, or usefulness of any information, apparatus, product, or process disciosed, or represents that its use would not infringe privately owned rights. Reference herein to any specific commercial product, process, or service by trade name, trademark, manufacturer, or otherwise does not necessarily constitute or imply its endorsement, recommendation, or favoring by the United States Government or any agency thereof. The views and opinions of authors expressed herein do not necessarily state or reflect those of the United States Government or any agency thereof. 


\section{DISCLAIMER}

Portions of this document may be illegible in electronic image products. Images are produced from the best available original document. 


\title{
Real-Time Monitoring of Laser Surface Hardening of Ferrous Alloys
}

\author{
Zhiyue Xu1, Keng H. Leong2 and Claude B. Reed 1 \\ 1Technology Development Division, Argonne National Laboratory, \\ 9700 S. Cass Avenue, Building 360, Argonne, II 60439 \\ 2Applied Research Laboratory, The Pennsylvania State University \\ State College, PA 16804
}

\begin{abstract}
An infrared process monitor was used to monitor in real-time the infrared emissions during laser surface hardening of gray cast iron and 1045 steel. The signal from the monitor was correlated with the hardness and case depth of the laser-treated tracks. Test data show that a linear relationship exists between the monitor output DC level voltage and hardness up to the maximum hardness possible and also between the monitor output DC level voltage and case depth. This simple relationship of the monitor voltage signal with hardness and case depth makes it easy to monitor process hardness, case depth and quality. A calibration test on prototypic material can be used to determine at what voltage level melting occurs and the heat treating process hardness and case depth can be monitored easily by setting an upper and lower bound for the voltage signal. The monitor is also capable of tracking changes in surface quality or flatness of the part that is being treated.
\end{abstract}

\section{INTRODUCTION}

In mechanical systems, many moving components such as cam or ring gears must have a very hard surface to resist wear, along with a tough interior to resist the impact that occurs during operation. One of widely used processing techniques to realize the above combination of hard surface and tough interior is transformation surface hardening of the material, i.e. selective austenitization and martensitation of local surface region by rapid heating and cooling. The conventional methods used to harden the surface of the ferrous materials include flame and induction hardening. Case hardened depths of several millimeters are obtained but with significant thermal distortion of the components such that rework is usually required.[1,2] Laser transformation surface hardening is an alternate technique that selectively hardens the wear surface only with the rest of the component providing the heat sink. This self-quenching eliminates the need to use oil or water quenching baths. Most attractively, laser surface hardening generates low thermal distortion so refinishing of the part can be eliminated. As the use of laser surface hardening technology increases, so does the need for reliable methods for process monitoring.

The characteristic optical and acoustic signals associated with the laser welding process are well understood. Researchers have implemented various forms of weld monitoring to collect the signals and correlate them with variations in weld quality.[3-6] Leong integrated an infrared emission detector into the beam delivery optics to monitor the infrared weld signal.[3] Sanders and Leong tested in detail the infrared weld monitor technique as a welding process monitor and correlated the simple analog output with weld penetration, weld surface quality, and surface contamination with mistagging of good welds minimized.[4] In-process monitoring or real-time non-destructive measurement of the depth of the laser transformation hardened zone has not yet been achieved. Instead, Miller and Wineman[7] used the manganese phosphate coating on the steering gear housing as the basis of a visual quality control. A bluish-black coloring of the treated area, surrounded by a gray border is used to indicate a satisfactory treatment. In this study, the 
same infrared weld monitor used to monitor laser welding is used to monitor the infrared emissions from laser beam surface hardening of ferrous alloys. The signals from the monitor then are correlated with the hardness of the laser-treated tracks. A calibration test on prototypic material can be used to determine at what voltage level melting occurs and the heat treating process hardness can be monitored easily by setting an upper and lower bound for the voltage signal.

\section{EXPERIMENTAL PROCEDURES}

A pulsed $2 \mathrm{~kW} \mathrm{Nd:YAG} \mathrm{laser} \mathrm{(modified} \mathrm{Elctrox)} \mathrm{with} \mathrm{fiber} \mathrm{optic} \mathrm{beam} \mathrm{delivery} \mathrm{through} \mathrm{a}$ $1000 \mu \mathrm{m}$ step-index fiber was used. The output optics consist of a spherical collimating lens with a combination of a $127 \mathrm{~mm}$ FL cylindrical lens and a $75 \mathrm{~mm}$ FL spherical lens as shown in Figure 1. An oval beam profile was achieved by the combination. The oval beam profile was chosen because of the aspect ratio and the steepness of the irradiance gradient along the minor axis (the beam was translated parallel to the major axis) for optimal heat treatment. Treated tracks were made on 1045 steel and gray cast iron (3.10-3.50 wt\% carbon content) at beam travel speeds ranging from 1 to 5 $\mathrm{cm} / \mathrm{s}$ provided by moving the workpiece on a X-Y table under the stationary laser head. The average power was 1200 watts ( $3.0 \mathrm{~kW}$ peak power) at the workpiece, in which the pulse width was $2 \mathrm{~ms}$ and the repetition rate was $200 \mathrm{~Hz}$. The pulse parameters were set to simulate the effect of a cw laser taking into account the thermal relaxation time of the metal. The same pulse settings were used for both alloys. The oval beam, after being defocused, had a minor axis of $4 \mathrm{~mm}$ and major axis of $6 \mathrm{~mm}$. The area of the oval beam was $0.75 \mathrm{~cm}^{2}$, giving a peak irradiance of the beam of $3.9 \mathrm{~kW} / \mathrm{cm}^{2}$. Top gas shielding was provided by a $25 \mathrm{lpm}$ flow of nitrogen in a trailing jet configuration delivered by a $0.8 \mathrm{~cm}$ diameter tube oriented at 150 from the surface and 450 from

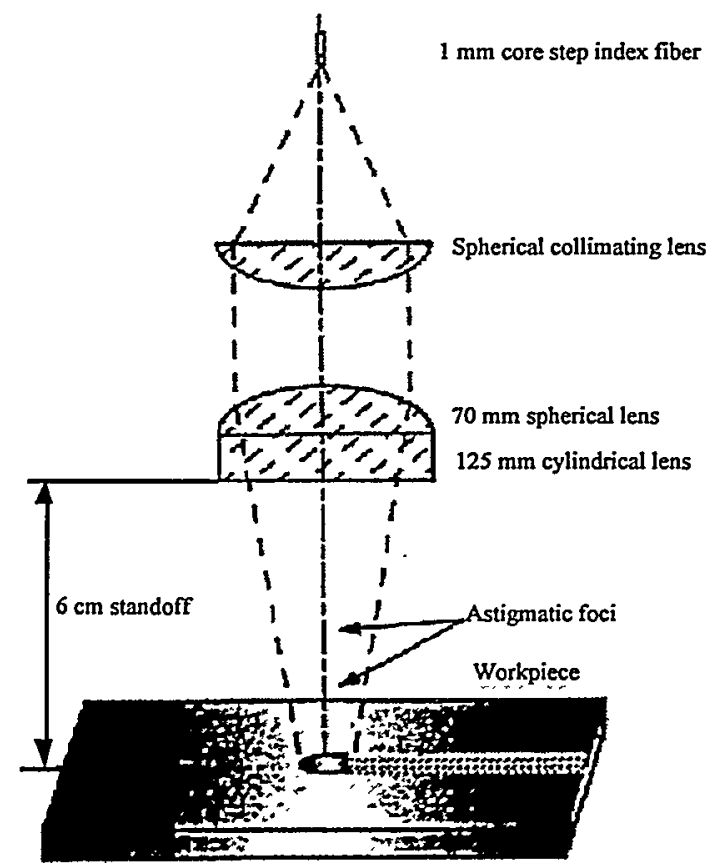

Figure 1 Layout of lenses used for heat treatment with Nd:YAG system

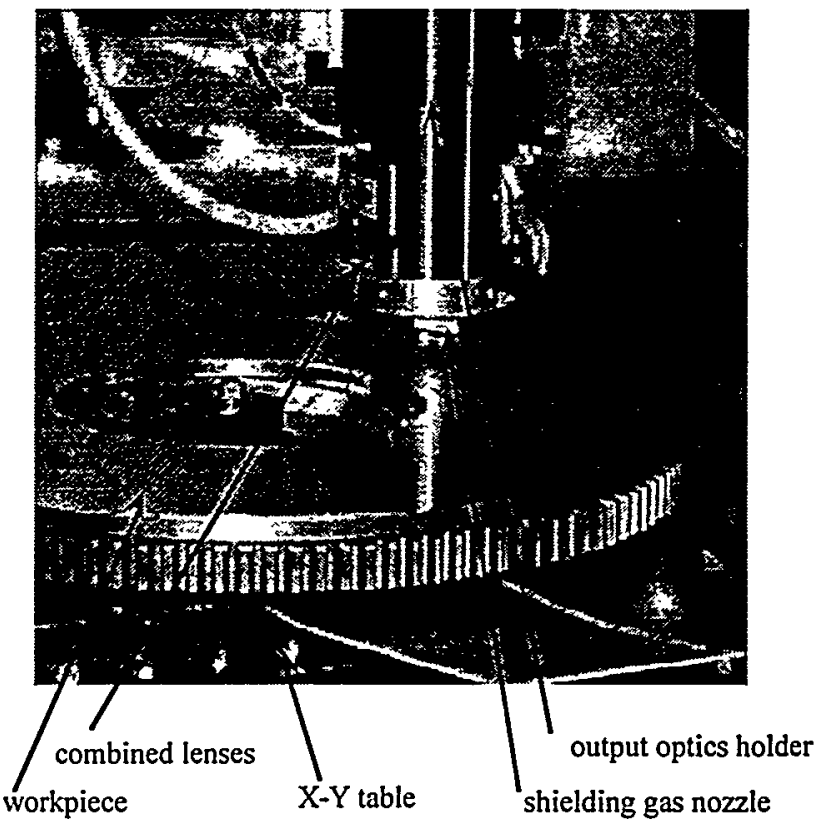

Figure 2 Annotated photograph of Nd:YAG laser surface hardening 
the horizontal and $1 \mathrm{~cm}$ from the beam spot. The annotated photograph of the set-up of YAG laser surface hardening is shown in Figure 2. An infrared weld monitor, successfully used to monitor weld quality ,[3,4] was utilized to monitor the process of surface hardening. The monitor was integrated into the Nd:YAG beam delivery optics and used oversized, off-axis optics to collect the infrared emission signal associated with laser beam surface hardening. Monitor output voltages as a function of time were collected using data acquisition hardware and software (GW Instruments, Somerville, MA) with an Apple Macintosh computer. The data collection rate used was 2500 to $5000 \mathrm{~Hz}$. The monitor system noise (standard deviation) when not surface treating was $0.20 \mathrm{mV}$. The Rockwell $\mathrm{C}$ hardnesses along the treated tracks were measured using a portable hardness tester.Case depths of treated tracks were determined by measuring the hardness on cross-sectioned samples. The corresponding monitor voltage for each hardness or case depth measurement on a treated track was obtained from the monitor voltage-time plot.

\section{RESULTS AND DISCUSSION}

Figure 3 shows the raw data from the monitor where the voltage is plotted versus time obtained for a series of tests carried out with the high power pulsed Nd:YAG laser on gray cast iron. The closely spaced pulses are the dark upper part of the chart and the DC level is the top of the white light portion of the chart. The pulses are a consequence of the pulsed beam and would not be present if a cw laser is used. The bulk hardness, case depth and the corresponding monitor output DC level voltages at various beam travel speeds are tabulated in Tables 1 and 2 for gray cast iron and 1040 steel respectively. A column indicates whether melting of the surface occurred at low travel speeds. The cast iron alloy is more difficult to harden without surface melting because a significantly longer time-at-temperature is required to diffuse carbon atoms from the graphite flakes into the matrix during laser heating.[8,9,10] Plots of the bulk hardness versus monitor DC voltage level for the two alloys are shown in Figs. 4 and 5. The plots of the case depth versus monitor DC voltage level for the two materials are shown in Figs. 6 and 7. The raw data for the monitor output shows that a stable voltage is produced for treated tracks that achieved substantial hardness or case depth. In fact a linear relationship exists between voltage and hardness up to the maximum hardness possible or case depth. The high R-squared values indicate the quality of the fit. Some additional increase of hardness is provided when melting occurs. This simple relationship of the monitor voltage signal with hardness and case depth makes it easy to monitor process hardness and quality.

A calibration test on prototypic material can be used to determine at what voltage level melting occurs and the heat treating process hardness can be monitored easily by setting an upper and lower bound for the voltage signal. Figure 8 shows the calibration curve for laser surface hardening of 1045 steel. The threshold melting voltage level is $450 \mathrm{mV}$. The range of data error bars for the bounds is $\pm 10 \mathrm{mV}$. For instance, if the required surface hardness is around HRC 50 , according to the calibration curve, the monitor DC voltage output level should be within the range of 355 to $375 \mathrm{mV}$. The DC voltage level can then be controlled by varying beam travel speed or beam pulse parameters.

Figures 9 shows the heat treated tracks produced on a gray cast iron component. The horizontal tracks are obtained before the vertical tracks in Fig. 9. Figure 10 is the raw data from the weld monitor for the wider vertical track on the middle of the photo. The additional melting and small surface change are indicated in the monitor output by the corresponding "bumps" in the data. The "low" bump at the beginning of the data for the cast iron case is caused by the depression in the component at the top part of the photo. Hence, the monitor also tracks changes in surface quality or flatness of the part that is being treated. 


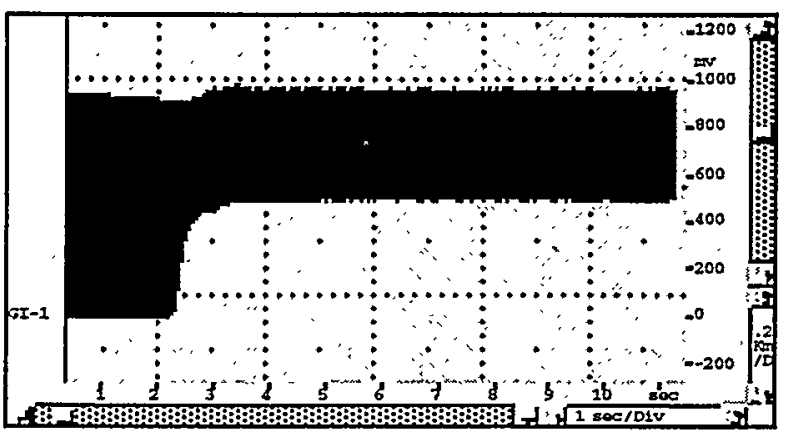

(a)

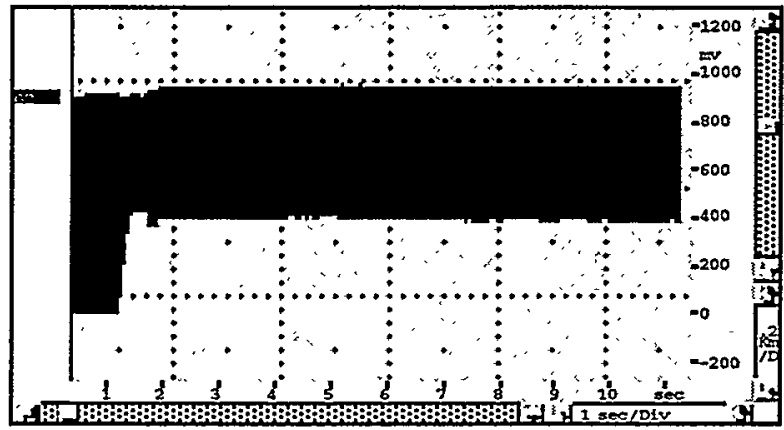

(c)

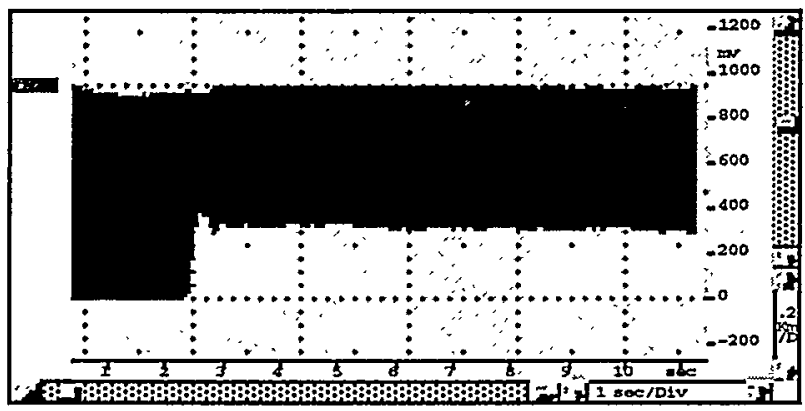

(e)

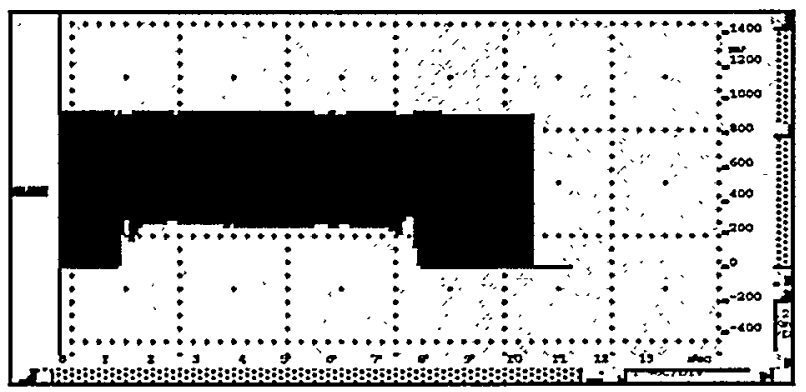

(g)

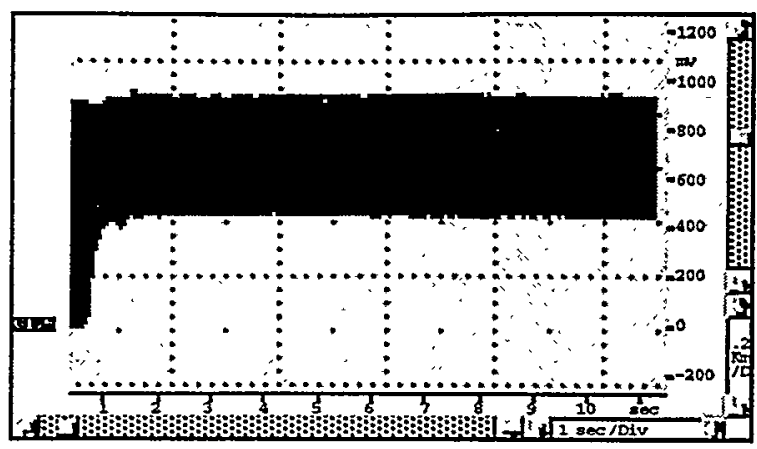

(b)

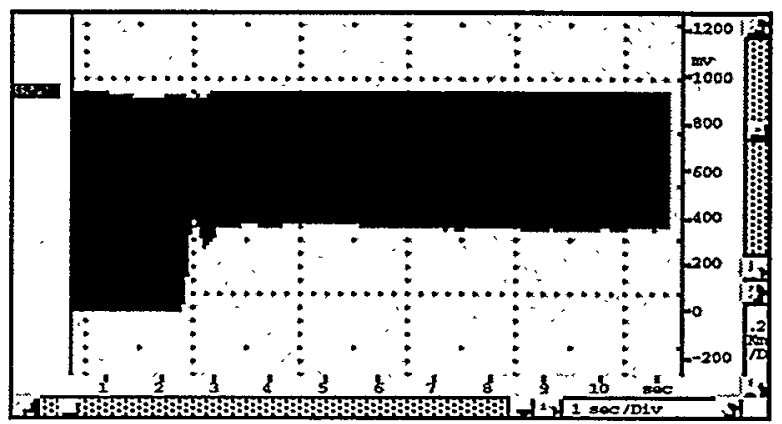

(d)

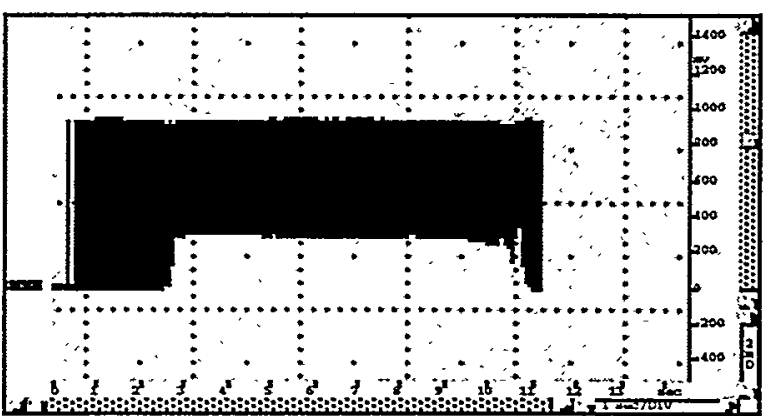

(f)

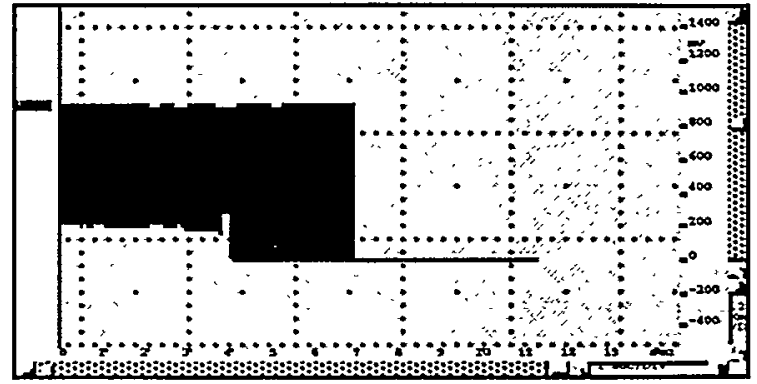

(h)

Figure 3 Monitor signals of surface hardening of gray cast iron at beam travel speed of (a) $1 \mathrm{~cm} / \mathrm{s}$, (b) $1.5 \mathrm{~cm} / \mathrm{s}$, (c) $2 \mathrm{~cm} / \mathrm{s}$, (d) $2.5 \mathrm{~cm} / \mathrm{s}$, (e) $3 \mathrm{~cm} / \mathrm{s}$, (f) $3.5 \mathrm{~cm} / \mathrm{s}$, (g) $4 \mathrm{~cm} / \mathrm{s}$, and (h) $5 \mathrm{~cm} / \mathrm{s}$. 
Table 1. Monitor signal and hardness of gray cast iron

\begin{tabular}{|c|c|c|c|c|}
\hline $\begin{array}{c}\text { Travel speed } \\
(\mathrm{cm} / \mathrm{s})\end{array}$ & $\begin{array}{c}\text { Monitor } \\
\text { signal (mv) }\end{array}$ & Case depth (mm) & Hardness (HRC) & Molting (Y/N) ? \\
\hline 1 & 500 & 0.74 & 51 & $\mathrm{Y}$ \\
\hline 1.5 & 460 & 0.67 & 47 & $\mathrm{Y}$ \\
\hline 2 & 400 & 0.61 & 40 & slightly \\
\hline 2.5 & 360 & 0.5 & 33 & $\mathrm{~N}$ \\
\hline 3 & 310 & 0.41 & 27 & $\mathrm{~N}$ \\
\hline 3.5 & 280 & 0.32 & 25 & $\mathrm{~N}$ \\
\hline 4 & 250 & 0.29 & $<20$ & $\mathrm{~N}$ \\
\hline 5 & 200 & 0.20 & $<20$ & $\mathrm{~N}$ \\
\hline
\end{tabular}

Table 2 Monitor signal and hardness of 1045 steel

\begin{tabular}{|c|c|c|c|c|}
\hline $\begin{array}{l}\text { Travel speed } \\
\text { (cm/s) }\end{array}$ & $\begin{array}{l}\text { Monitor signal } \\
\text { (mv) }\end{array}$ & Cass depth (mm) & Hardness (HRC) & Molten $(\mathrm{Y} / \mathrm{N})$ ? \\
\hline 1 & 540 & 1.2 & 62.5 & $\mathrm{Y}$ \\
\hline 1.5 & 520 & 0.95 & 62 & $Y$ \\
\hline 1.8 & 500 & 0.83 & 61.5 & $\mathrm{Y}$ \\
\hline 2 & 480 & 0.75 & 61 & slightly \\
\hline 2.5 & $\begin{array}{l}380 \\
390 \\
410 \\
440\end{array}$ & 0.63 & $\begin{array}{l}55 \\
59 \\
60 \\
61\end{array}$ & $\mathrm{~N}$ \\
\hline 3 & $\begin{array}{l}250 \\
290 \\
350 \\
380 \\
\end{array}$ & 0.51 & $\begin{array}{l}30 \\
37 \\
45 \\
56\end{array}$ & $\mathbf{N}$ \\
\hline 3.5 & $\begin{array}{l}150 \\
180 \\
230 \\
300 \\
330\end{array}$ & 0.43 & $\begin{array}{l}24 \\
26 \\
31 \\
42 \\
48\end{array}$ & $\mathrm{~N}$ \\
\hline 4 & $\begin{array}{c}80 \\
100 \\
130 \\
200 \\
250\end{array}$ & 0.32 & $\begin{array}{l}<20 \\
<20 \\
22 \\
25 \\
28\end{array}$ & $\mathrm{~N}$ \\
\hline
\end{tabular}




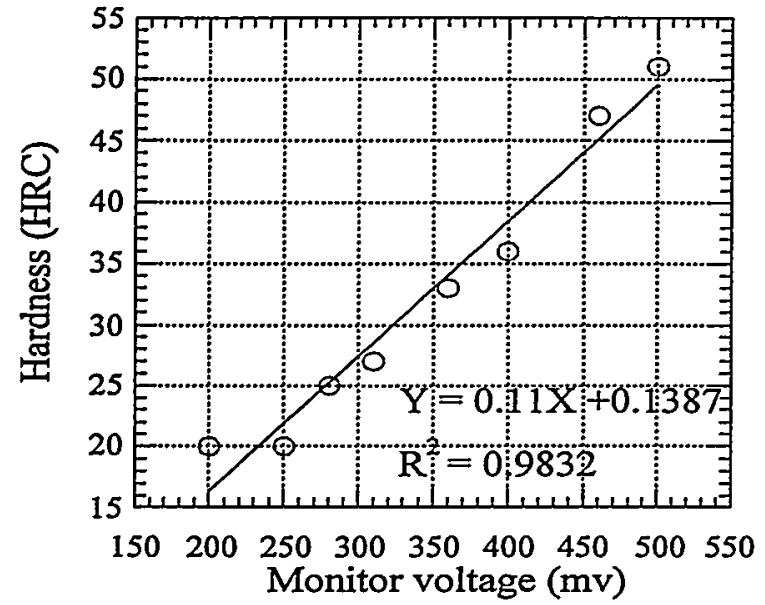

Figure 4 Plot of average bulk hardness versus the corresponding monitor DC voltage level for gray cast iron.

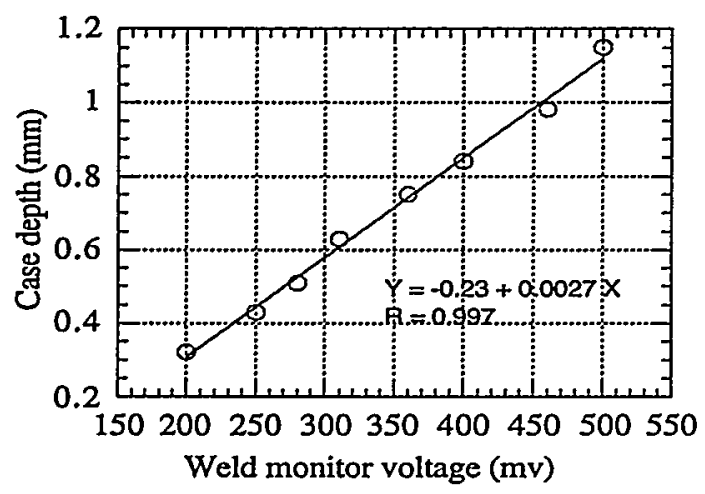

Figure 6 Plot of case depth versus the corresponding monitor DC voltage level for 1045 steel.

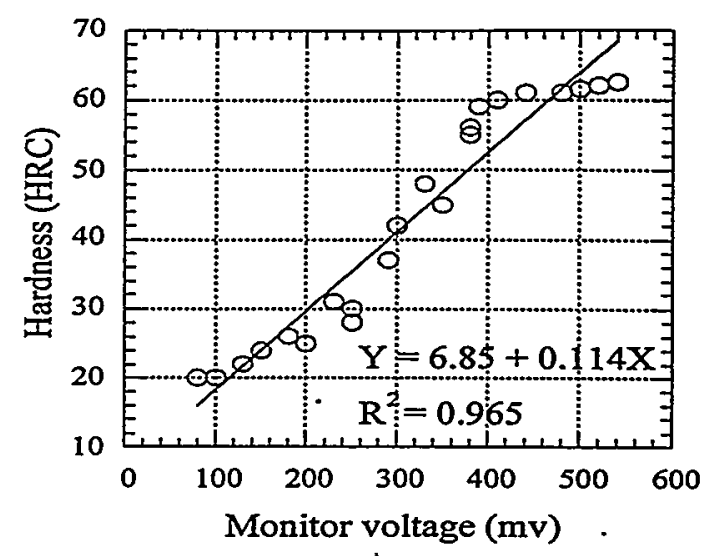

Figure 5 Plot of average bulk hardness versus the corresponding monitor DC voltage level for 1045 steel.

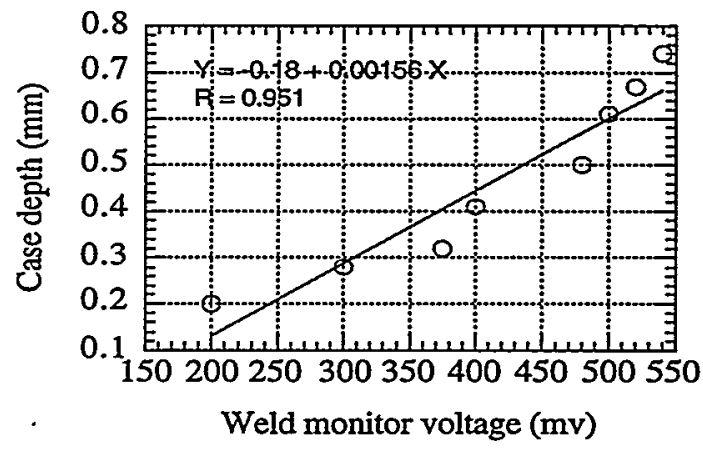

Figure 7. Plot of case depth versus monitor DC voltage level for gray cast iron

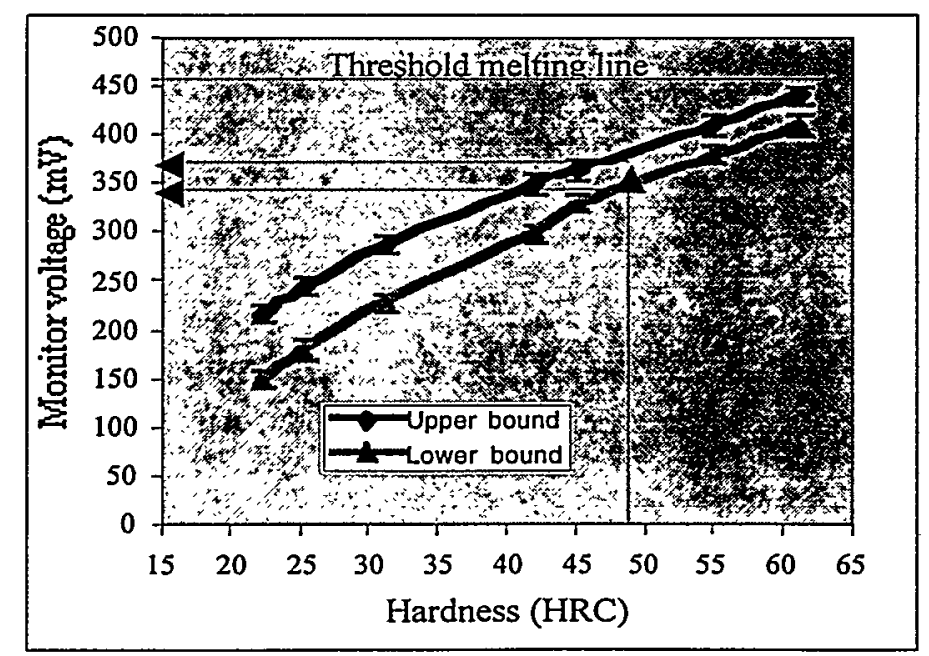

Figure 8 The calibration curve for laser surface hardening of 1045 steel 


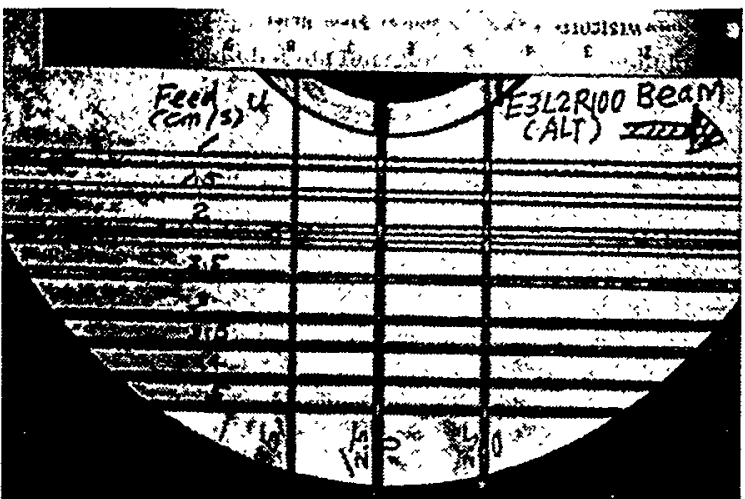

Figure 9 Photograph showing the laser heat treated tracks produced on a gray cast iron component

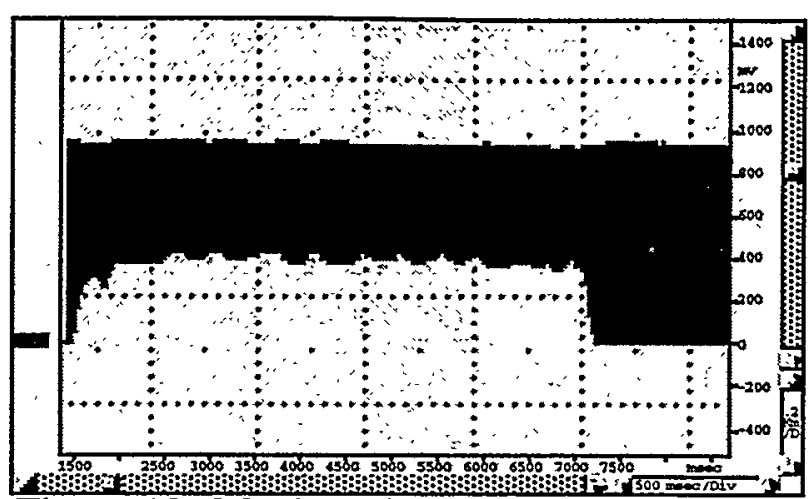

Figure 10 Monitor signal obtained from the vertical track in Fig. 9 at beam travel speed of $2.5 \mathrm{~cm} / \mathrm{s}$

\section{CONCLUSIONS}

The test data obtained showed that the infrared weld monitor invented at Argonne National Laboratory for process monitoring of laser welding is also capable of monitoring the process of laser surface hardening. This linear relationship of the monitor voltage signal with hardness and case depth makes it easy to monitor process hardness, case depth and quality. It is also shown by the raw test data that the monitor is capable of tracking changes in surface quality or flatness of the workpiece that is being treated.

\section{ACKNOWLEDGMENTS}

This work was funded by the U.S. Department of Energy, Office of Energy Research Laboratory Technology Research Program and the Office of Transportation Technologies.

\section{REFERENCES}

1. S. Lampman, "Introduction to surface hardening of steels," ASM Handbook, Vol. 4, Heat Treating, ASM International, Materials Park, OH. 1997, pp. 259-267.

2. T. Ruglic, "Flame hardening," ASM Handbook, Vol. 4, Heat Treating, ASM International, Materials Park, OH. 1997, pp. 268-285.

3. K. H. Leong, "Low cost laser weld monitoring system," Proceedings of the Automotive Laser Applications Workshop, 1997, Novi, MI., 4-5 March, 1997.

4. P.G. Sanders, K. H. Leong, J. S. Keske, and G. Korneck, "Real-time monitoring of laser beam welding using infrared weld emissions," J. Laser Appl., Vol. 10, No., 5, October 1998.

5. H. B. Chen, L. Li, D. J. Brookfield, K. Williams, and W. M. Steen, "Laser process monitoring with dual wavelength sensors," Proc. ICALEO 91, San Jose, CA., 1991.

6. D. U. Chang, "Monitoring laser weld quality in real time," Indust. Laser Rev. 15 November, 1994.

7. J. E. Miller and J. A. Wineman, "Laser hardening at Saginaw Steering Gear," Metal Progress, May 1977, Vol. 111, (5), pp. 38-43.

8. V. G. Gregson, "Laser heat treatment," Chap. 4, Materials Processing, edited by M. Bass, Holland Publishing Company, 1983.

9. O. A. Sandven, "Laser surface hardening," ASM Handbook, Vol. 4, Heat Treating, ASM International, Materials Park, OH. 1997, pp. 286-296.

10. P. J. Oakley, "Review of laser heat treatment and surface techniques," Research report, The Welding Institute, November, 1980. 